\title{
SOBREVIVÊNCIA E CRESCIMENTO DE SEIS ESPÉCIES ARBÓREAS SUBMETIDAS A QUATRO TRATAMENTOS EM ÁREA MINERADA NO CERRADO ${ }^{1}$
}

\author{
Lucas de Carvalho Ramos Silva² e Rodrigo Studart Corrêa ${ }^{3}$
}

\begin{abstract}
RESUMO - Entre as várias atividades antrópicas desenvolvidas no Cerrado, a mineração é uma das que provocam significativos danos. A regeneração natural da vegetação em áreas mineradas é extremamente lenta e, portanto, a intervenção em lavras esgotadas faz-se necessária. O presente trabalho objetiva avaliar a sobrevivência e o crescimento de mudas de seis espécies arbóreas, submetidas a quatro tratamentos, usadas na revegetação de uma cascalheira em Brasília-DF. Os quatro tratamentos consistiram da combinação da utilização de cobertura morta sobre as covas e/ou o plantio de árvores em substrato coberto por Stylosanthes spp. Um tratamento controle, localizado em área adjacente não minerada, foi estabelecido para efeitos comparativos. Os resultados indicam que as mudas arbóreas implantadas na área minerada apresentaram maior sobrevivência e crescimento do que as mesmas espécies plantadas na área controle não minerada. Na área minerada não foram verificadas diferenças significativas no desenvolvimento das espécies em função dos tratamentos aplicados - cobertura morta sobre covas e/ou estrato herbáceo sobre a superfície minerada.
\end{abstract}

Palavras-chave: Recuperação, revegetação e mineração.

\section{SURVIVAL AND GROWTH OF SIX TREE SPECIES UNDER FOUR TREATMENTS ON A MINED AREA IN THE BRAZILIAN SAVANNA}

\begin{abstract}
Among many human activities developed in areas of Brazilian savanna, mining is one that causes significative damage to the environment. Natural sucession on such sites is extremely slow and therefore revegetation works are necessary. This work aims to evaluate survival and growth of six tree species under four treatments grown on an exploited gravel mine in the Brazilian Federal District. The four treatments were drawn from the combination of mulching around tree seedlings and the establishment of Stylosanthes spp on the area surface. A control was established on a nearby unexploited for comparison reason. Results show a higher survival rate and growth of tree seedlings established on the exploited site than on the controlsite which kept intact soil. There were no significant differences for survival and growth among trees established on the gravel mine under the four treatments - combined mulching and/or herbaceous layer on gravel mine surface.
\end{abstract}

Keywords: Restoration, revegetation and mining.

\section{INTRODUÇÃO}

O Distrito Federal situa-se na porção central do Cerrado brasileiro, onde é intenso o conflito entre medidas conservacionistas e as atividades econômicas. Além dos danos causados pela agropecuária e a urbanização, aproximadamente $0,6 \%$ do território distrital foram degradados pela exploração mineral nos últimos 45 anos, percentagem cinco vezes superior à média nacional (Corrêa et al., 2004). Sucessões ecológicas sobre substratos recém-expostos e sem prévia influência biológica, como ocorrem em áreas mineradas, são ditas primárias. Esse tipo de sucessão leva séculos para atingir uma comunidade clímax (BEGON et al., 1990).

\footnotetext{
${ }^{1}$ Recebido em 24.06.2006 e aceito para publicação em 19.05.2008.

${ }^{2}$ EMBRAPA Cerrados - CPAC, Brasília-DF. E-mail: <lucascrs@cpac.embrapa.br>.

${ }^{3}$ Departamento de Engenharia Florestal da Universidade de Brasília (UNB), Brasília-DF. E-mail: <rodmanga@yahoo.com.br> .
} 
Dessa forma, a interferência humana é necessária para promover a aceleração do processo de regeneração natural nas áreas mineradas.

A descaracterização de ecossistemas pelo homem tem colocado diversas espécies sob o risco de extinção. Planos conservacionistas para pequenas populações silvestres recomendam a restauração de comunidades vegetais como forma de aumentar a capacidade de suporte do ambiente. A restauração inicia-se com a criação de condições que impulsionem os caminhos da sucessão (ANAND e DESROCHERS, 2004), e os trabalhos de revegetação de áreas mineradas iniciam-se com a estabilização da paisagem e a introdução de uma cobertura vegetal no local. Há vários anos vigora no Brasil a exigência legal de se recuperar áreas degradadas pela mineração, mas ainda subsistem dificuldades técnicas para tornarem eficazes medidas de revegetação desses locais (ALMEIDA e SÁNCHEZ, 2005).

De acordo com KAGEYAMAe GANDARA(2001), a aceleração da regeneração de ambientes degradados pode ser alcançada por meio do plantio de espécies arbóreas. Entretanto, há a necessidade de se aprimorarem as técnicas de plantio, principalmente quando se tratam de espécies nativas em áreas mineradas no Cerrado, pois muitos projetos não têm apresentado resultados satisfatórios. Nesse sentido, faz-se necessário investigar técnicas e práticas que proporcionem uma maior sobrevivência e um melhor desenvolvimento de espécies introduzidas em ambientes agudamente degradados.

Segundo BORGES et al. (1995), a utilização de cobertura morta (mulch) em covas de mudas arbóreas reduz severamente a evapotranspiração e traz benefícios para as plantas. OLIVEIRA e SOUZA (2003) constataram a manutenção da umidade no solo e o efeito inibidor de ervas invasoras em covas cobertas por mulch. Portanto, a utilização dessa técnica em sítios minerados apresenta o potencial de reduzir o número de mudas mortas e de promover maior crescimento de espécies arbóreas, pois, teoricamente, cobertura morta (mulch) depositada sobre a superfície de covas aumenta a água disponível para as plantas.

A escarificação ou subsolagem para a introdução de uma camada rasteira sobre substratos minerados pode favorecer o desenvolvimento das raízes de árvores plantadas no local, uma vez que as raízes dessas plantas podem extrapolar o volume da cova e explorar o substrato superficial que fora tratado para a introdução de plantas herbáceas (BITAR, 1997). De acordo com MALTONI e VALÉRIO (2000), a revegetação de áreas de empréstimo com espécies forrageiras nativas tem-se mostrado muito benéfica para o ecossistema, principalmente em se tratando de leguminosas.

A leguminosa estilosante (Stylosanthes spp.) apresenta espécies forrageiras de ocorrência natural no Cerrado, que as habilita para o uso em áreas onde a utilização de espécies nativas seja uma exigência. A maioria das espécies do gênero Stylosanthes é perene, com potente sistema radicular, tolerante à seca, de grande capacidade colonizadora de solos de baixa fertilidade e são inoculadas por fixadoras de nitrogênio (EMBRAPA, 1993; SILVA e ZIMMER, 2004). Apesar disso, não existem estudos que avaliem os efeitos da consórciação de Stylosanthes spp. com espécies arbóreas nativas do Cerrado na recuperação de áreas mineradas.

Dessa forma, este trabalho visa avaliar a sobrevivência e o crescimento de seis espécies arbóreas de Cerrado, submetidas a quatro diferentes tratamentos, em uma área minerada no Distrito Federal.

\section{MATERIAL E MÉTODOS}

O experimento consistiu em testar o efeito de quatro tratamentos aplicados ao substrato de uma cascalheira sobre a sobrevivência e o crescimento em altura e diâmetro de seis espécies arbóreas de Cerrado (Quadro 1). O projeto foi instalado em uma antiga jazida explotada, situada na Área de Relevante Interesse Ecológico Santuário de Vida Silvestre do Riacho Fundo, Distrito Federal - coordenadas 1552'05'”S e 4756'54'”W. A cava, lavrada na década de 1970, apresenta extensão de 1,5 ha, Cambissolo como solo original (EMBRAPA, 1999) e cerca de um metro de profundidade de corte. A área foi terraceada em 2002 e, até a instalação do experimento em setembro-novembro de 2003, não havia sinais de regeneração da vegetação no local. Metade da área total da cava, porção norte, foi escarificada a $20 \mathrm{~cm}$ de profundidade, adubada com $20 \mathrm{~m}^{3} \mathrm{ha}^{-1}$ de composto de lixo (Quadro 2), $870 \mathrm{~kg} \mathrm{ha}^{-1}$ de calcário dolomítico 90\% PRNT e 435 kg ha-1 de NPK - 4:14:8. Quinze dias após à aplicação dos insumos, foram incorporados $2 \mathrm{~kg} \mathrm{ha}^{-1}$ de sementes de Stylosanthes spp. (mineirão) à profundidade de $5 \mathrm{~cm}$, para a implantação de um estrato herbáceo. Para o plantio das mudas, covas de $64 \mathrm{~L}(0,4$ x 0,4 x 0,4 m) foram abertas manualmente no espaçamento $4 \times 4 \mathrm{~m}$. 
Quadro 1 - Principais características das espécies utilizadas Table 1-Main characteristics of the employed species

\begin{tabular}{|c|c|c|c|c|}
\hline Espécie & Nome Popular & Família & Ecologia & Habitat \\
\hline Inga marginata & Ingá & Fabaceae (Leguminosae) & pioneira & Mata de Galeria \\
\hline Couepia grandiflora & Oiti & Chrysobalanaceae & secundária & $\begin{array}{l}\text { Cerrado s.s., } \\
\text { Campo Rupestre e } \\
\text { Mata de Galeria }\end{array}$ \\
\hline Genipa americana & Jenipapo & Rubiaceae & pioneira & Cerrado s.s. e Cerradão \\
\hline Hymenaea stigonocarpa & Jatobá-do-Cerrado & Fabaceae (Leguminosae) & $\begin{array}{l}\text { secundária } \\
\text { tardia }\end{array}$ & $\begin{array}{c}\text { Cerradão, Cerrado s.s., } \\
\text { Campo Sujo, Mata de galeria }\end{array}$ \\
\hline Kielmeyera lathrophytum & Pau-santo & Clusiaceae (Guttiferae) & secundária & $\begin{array}{l}\text { Cerrado s.s., Campo Limpo, } \\
\text { Campo Sujo e Mata de Galeria }\end{array}$ \\
\hline Tapirira guianensis & Pau-pombo & Anacardiaceae & pioneira & Mata de Galeria e Cerradão \\
\hline
\end{tabular}

Fonte: Felfili et al. (2004); Mendonça et al. (1998); Motta et al. (1997); Lorenzi (1992); Durigan e Nogueira (1990).

O substrato minerado da porção sul da cava não recebeu qualquer tratamento, exceto a abertura de covas de mesmas dimensões e espaçamento. Outras 36 covas, com mesmas dimensões e espaçamento, foram manualmente abertas em uma área de Cerrado sentido restrito, adjacente à área do experimento, para fins de controle (6 espécies x 6 repetições). O espaçamento entre mudas utilizado no experimento refere-se à densidade média de 625 indivíduos lenhosos/ha presentes em áreas nativas do Distrito Federal (Eiten, 1994; 2001). As covas foram abertas e adubadas em setembro de 2003 e o plantio das árvores e a semeadura do estilosante foram executados em novembro de 2003, quando do firmamento das chuvas. As mudas utilizadas foram produzidas no viveiro da Secretaria de Agricultura do Distrito Federal, tendo na data do plantio entre 20 e $40 \mathrm{~cm}$ de altura, conforme a espécie. As sementes certificadas de estilosante (mineirão) obtidas no comércio local consistem de uma mistura de Stylosanthes capitata, S. guianenses e $S$. macrocephala.

A caracterização química do composto utilizado, do substrato minerado, do substrato tratado e do solo da área controle encontra-se no Quadro 2. Todas as covas receberam $30 \mathrm{~L}$ de composto de lixo (densidade = 0,4 $\mathrm{Mg} \mathrm{cm}^{-3}$ ), 100 g de calcário dolomítico (90\% PRNT), 100 g de NPK- 4:14:8 e 10 g de FTE (fonte de micronutrientes). Aproximadamente trinta dias após o plantio das mudas, foram aplicados à superfície de cada cova 100 g de NPK-10:10:10, como adubação de cobertura. O composto de lixo utilizado foi produzido a partir da compostagem em leiras de aeração passiva do lixo doméstico de Brasília, na Usina de Lixo de Ceilândia - DF, operada pela empresa Qualix. Os insumos aplicados às covas e na metade norte da superfície da área minerada visaram melhorar as condições químicas, físicas e biológicas do substrato minerado por meio da elevação dos teores de matéria orgânica e nutrientes a valores próximos aos observados em Cambissolos eutróficos (GOEDERT e Corrêa, 2004).

As espécies arbóreas utilizadas (Quadro 1) foram selecionadas a partir de listas elaboradas por Corrêa e MÉLO FILHO (1998), que testaram o comportamento de várias espécies em áreas mineradas no Distrito Federal. As mudas árbóreas foram plantadas em grupos de seis indivíduos (um de cada espécie), com doze repetições na metade norte da área de estudo (coberta com estrato herbáceo) e doze repetições implantadas na metade sul da área, onde a superfície do substrato minerado não foi tratada. Seis grupos entre os doze implantados em cada porção da área (metade sul e metade norte) receberam cavaco de madeira no coroamento da cova (mulching). Os demais seis grupos em cada porção da área de estudo não receberem cavaco de madeira sobre a superfície da cova. Outros seis grupos de seis espécies (36 mudas) foram implantados na área de solo intacto, ao lado da área minerada, para efeitos de controle. Dessa forma, definiram-se os tratamentos $\mathrm{T}_{\mathrm{c}}, \mathrm{T}_{1}, \mathrm{~T}_{2}, \mathrm{~T}_{3}$ e $\mathrm{T}_{4}$ abaixo, cada um contando com 36 plantas (6 espécies x 6 repetições):

$\mathbf{T}_{\mathbf{c}}$ - controle: covas adubadas em solo não minerado.

$\mathbf{T}_{\mathbf{1}}$ - covas adubadas na área minerada, sem estrato herbáceo sobre a área e sem utilização de cobertura morta no coroamento das mudas (mulching).

$\mathbf{T}_{2}$ - covas adubadas na área minerada, sem estrato herbáceo sobre a área e com mulching (50 L/cova).

$\mathbf{T}_{3}$ - covas adubadas na área minerada, com estrato herbáceo sobre a área e sem mulching. 
$\mathbf{T}_{4}$ - covas adubadas na área minerada, com estrato herbáceo sobre a área e com mulching (50 L/cova).

Sobrevivência, crescimento em altura e em diâmetro de todas as plantas foram mensurados durante duas estações de crescimento para se avaliar o efeito do estrato herbáceo e do mulching sobre o desenvolvimento das árvores. A altura das mudas foi determinada medindose a distância entre a base do caule e a gema apical de cada indivíduo. O diâmetro das plantas foi medido ao final da segunda estação de crescimento a $10 \mathrm{~cm}$ de altura do solo. Nas plantas bifurcadas, foram considerados os caules de maior diâmetro. Os dados obtidos foram analisados pelo programa Statistical Analysis System Institute, Inc. (SAS, 1999), adotandose o teste de Wilcoxon - signed rank test $(\mathrm{P}<0,05)$, alternativa não paramétrica equivalente ao teste-t de Student (Campos, 1979).

\section{RESULTADOS E DISCUSSÃO}

\subsection{Sobrevivência das mudas}

A percentagem de árvores sobreviventes ao final da segunda estação de crescimento atingiu 77,8\% do total de indivíduos plantados. ALMEIDA e SÁNCHEZ (2005) consideram mortalidade de $10 \%$ de mudas como referência em projetos de revegetação, apesar de esses autores terem verificado $38 \%$ de mudas mortas em dois projetos de revegetação de áreas mineradas no Estado de São Paulo. Segundo PIÑA-RODRIGUES et al. (1997), até $20 \%$ de mortes de mudas podem ser consideradas normais em projetos de revegetação de áreas mineradas.

De todas as mudas mortas neste trabalho, 71,8\% foram de uma única espécie - Kielmeyera lathrophytum (pau-santo). Apenas 6,7\% das mudas de pau-santo, espécie típica de Cerrado stricto sensu, sobreviveram até o final do experimento. As demais cinco espécies apresentaram sobrevivência superior a 90\% (Quadro 3). As plantas de K. lathrophytum que sobreviveram apresentaram clorose e necrose foliar. Algumas espécies de Cerrado não se desenvolvem bem quando adubadas com fertilizantes químicos, pois estão adaptadas às condições de solo mediamente ácido e deficiente em fósforo disponível (EMBRAPA, 1993). A elevação da fertilidade do substrato minerado é, portanto, a provável causa do reduzido número de sobreviventes da espécie K. lathrophytum.

Quadro 2 - Parâmetros químicos dos substratos e do solo para a profundidade de 0 a 20 cm e do lixo compostado (médias \pm desvio padrão)

Table 2 - Chemical parameters of substrates and soil at 0 - $20 \mathrm{~cm}$ depth and for the composted garbage (means \pm standard deviation)

\begin{tabular}{|c|c|c|c|c|}
\hline Parâmetro & Substrato não tratado & Substrato tratado & Solo controle & Composto de lixo \\
\hline $\mathrm{pH}_{\mathrm{H} 2 \mathrm{O}}(1: 2,5)$ & $6,71 \pm 0,18$ & $6,97 \pm 0,06$ & $5,72 \pm 0,11$ & $7,88 \pm 0,19$ \\
\hline M.O.* (g.kg-1) & $5,7 \pm 0,3$ & $13,4 \pm 0,5$ & $14,5 \pm 0,6$ & $112 \pm 8,7$ \\
\hline $\mathrm{N}\left(\mathrm{g} \cdot \mathrm{kg}^{-1}\right)$ & $0,6 \pm 0,0$ & $1,1 \pm 0,1$ & $1,0 \pm 0,1$ & $9,8 \pm 0,53$ \\
\hline $\mathrm{Ca}\left(\mathrm{cmol}_{\mathrm{c}} \cdot \mathrm{dm}^{-3}\right)$ & $1,67 \pm 0,19$ & $1,59 \pm 0,17$ & $1,17 \pm 0,06$ & $165 \pm 6,6$ \\
\hline $\mathrm{Mg}\left(\mathrm{cmol}_{\mathrm{c}} \cdot \mathrm{dm}^{-3}\right)$ & $0,24 \pm 0,02$ & $0,62 \pm 0,06$ & $0,26 \pm 0,01$ & $23,3 \pm 1,2$ \\
\hline $\mathrm{Al}\left(\mathrm{cmol}_{\mathrm{c}} \mathrm{dm}^{-3}\right)$ & 0,0 & 0,0 & 0,0 & $\longrightarrow$ \\
\hline $\mathrm{H}+\mathrm{Al}\left(\mathrm{cmol}_{\text {c. }} \mathrm{dm}^{-3}\right)$ & 0,0 & $0,16 \pm 0,14$ & $3,63 \pm 0,15$ & $\longrightarrow$ \\
\hline $\mathrm{K}\left(\mathrm{cmol}_{\mathrm{c} .} \mathrm{dm}^{-3}\right)$ & $0,04 \pm 0,01$ & $0,31 \pm 0,01$ & $0,14 \pm 0,0$ & $32,7 \pm 9,4$ \\
\hline $\mathrm{P}\left(\mathrm{mg} . \mathrm{kg}^{-1}\right)$ & $0,93 \pm 0,21$ & $11,26 \pm 2,70$ & $2,61 \pm 0,29$ & $1.200 \pm 350$ \\
\hline $\mathrm{Cu}\left(\mathrm{mg} \cdot \mathrm{kg}^{-1}\right)$ & $0,93 \pm 0,15$ & $1,97 \pm 0,23$ & $1,13 \pm 0,15$ & $128 \pm 40,5$ \\
\hline $\mathrm{Fe}\left(\mathrm{mg} \cdot \mathrm{kg}^{-1}\right)$ & $20,9 \pm 3,35$ & $41,7 \pm 2,81$ & $55,5 \pm 4,67$ & $464 \pm 22$ \\
\hline Mn (mg. kg $\left.{ }^{-1}\right)$ & $2,87 \pm 0,47$ & $7,47 \pm 0,49$ & $6,0 \pm 0,26$ & $304 \pm 36$ \\
\hline $\mathrm{Zn}\left(\mathrm{mg} \cdot \mathrm{kg}^{-1}\right)$ & $1,10 \pm 0,10$ & $8,43 \pm 0,31$ & $6,20 \pm 0,46$ & $527 \pm 81$ \\
\hline $\mathrm{S}\left(\mathrm{cmol}_{\mathrm{c}} \mathrm{dm}^{-3}\right)$ & 1,9 & 2,5 & 1,6 & $\longrightarrow$ \\
\hline CTC $\left(\mathrm{cmol}_{c} \mathrm{dm}^{-3}\right)$ & 1,9 & 2,7 & 5,2 & $\longrightarrow$ \\
\hline $\mathrm{V}(\%)$ & 100 & 94 & 30 & $\longrightarrow$ \\
\hline
\end{tabular}

*matéria orgânica.

*organic matter.

R. Árvore, Viçosa-MG, v.32, n.4, p.731-740, 2008 
Quadro 3 - Sobrevivência de mudas durante dezoito meses de desenvolvimento, considerando todos os tratamentos Table 3 - Plant survival through eighteen months of development, taking all treatments in account

\begin{tabular}{|c|c|c|c|c|}
\hline Espécie & $1^{\mathrm{a}}$ estação chuvosa & $1^{\text {a }}$ estação seca & $2^{\mathrm{a}}$ estação chuvosa & Total \\
\hline Inga marginata & $100 \%$ & $93,3 \%$ & $100 \%$ & $93,3 \%$ \\
\hline Hymenaea stigonocarpa & $96,7 \%$ & $93,3 \%$ & $100 \%$ & $90 \%$ \\
\hline Genipa americana & $100 \%$ & $96,7 \%$ & $100 \%$ & $96,7 \%$ \\
\hline Couepia grandiflora & $100 \%$ & $93,3 \%$ & $96,7 \%$ & $90 \%$ \\
\hline Tapirira guianensis & $100 \%$ & $90 \%$ & $100 \%$ & $90 \%$ \\
\hline Kielmeyera lathrophytum & $53,4 \%$ & $53,4 \%$ & $100 \%$ & $6,7 \%$ \\
\hline
\end{tabular}

Ao se analisar a sobrevivência por tratamento (Quadro 4), verifica-se que a área controle $\left(\mathrm{T}_{c}\right)$ apresentou o menor percentual de indivíduos sobreviventes. A literatura cita um grande número de interações positivas e negativas de vegetais, animais e microrganismos estabelecidos em um local, atuando sobre plântulas em vias de estabelecimento (GANADE e BROWN, 2002). Competição, parasitismo e predação são algumas dessas relações que parecem ter contribuído para a maior dificuldade do estabelecimento das mudas plantadas na área controle de Cerrado em relação à área minerada. Relações ecológicas desarmônicas são inexistentes em áreas mineradas, uma vez que os substratos expostos são estéreis. Outros autores têm obtidos resultados semelhantes de sobrevivência de mudas em áreas mineradas quando comparada a áreas não mineradas. Corrêa e MESQUITA (2004), por exemplo, constaram maior sobrevivência e crescimento de mudas de três espécies de Cerrado em área minerada do que em área com solo intacto.

Os menores percentuais de sobrevivência de mudas na área minerada referem-se aos tratamentos que utilizaram estrato herbáceo sobre a superfície - $\mathrm{T}_{3} \mathrm{e}$ $\mathrm{T}_{4}$ (Quadro 4). A sobrevivência das mudas nesses tratamentos foi inferior a 78\%, contra $83-86 \%$ de sobrevivência de mudas nos tratamentos que não receberam estrato herbáceo - $\mathrm{T}_{1}$ e $\mathrm{T}_{2}$. Dessa forma, a introdução de uma camada herbácea mostrou-se prejudicial ao estabelecimento das árvores na área minerada. A competição com o Stylozanthes spp. reduziu as chances de sobrevivência de algumas das mudas plantadas, independemente da espécie considerada.

As mudas do tratamento $\mathrm{T}_{2}$ (sem estrato herbáceo sobre a área, mas com cavaco sobre a cova) apresentaram o maior percentual de sobreviventes - 86,1\% entre todos os tratamentos. Esse valor é levemente superior ao tratamento $\mathrm{T}_{1}$, cuja única diferença em relação a $\mathrm{T}_{2}$ é a ausência de cavaco de madeira sobre as covas (Quadro 4). Manutenção da umidade no substrato das covas e, conseqüentemente, uma maior disponibilidade de água para as plantas são efeitos relatados quando se usa cobertura morta sobre covas (BORGES et al., 1995). Além disso, pôde-se observar que o cavaco de madeira inibiu a proliferação de outras espécies nas covas, como relatado por OLIVEIRA e SOUZA (2003). A análise da sobreviência das espécies por habitat de origem ou grupo ecológico não mostrou diferenças significativas entre as espécies de Mata de Galeria e as várias formas de Cerrado e Campo ou entre pioneiras e secundárias (Quadro 1).

Quadro 4 - Sobrevivência de mudas por tratamento durante dezoito meses de desenvolvimento Table 4 - Plant survival for each treatment through eighteen months of development

\begin{tabular}{|c|c|c|c|c|}
\hline Tratamentos & $1^{\text {a }}$ estação chuvosa & $1^{\text {a }}$ estação seca & $2^{a}$ estação chuvosa & Total \\
\hline$\overline{\mathrm{T}_{\mathrm{c}}}$ & $97,2 \%$ & $69,4 \%$ & $97,2 \%$ & $63,8 \%$ \\
\hline $\mathrm{T}_{1}$ & $86,1 \%$ & $97,2 \%$ & $100 \%$ & $83,3 \%$ \\
\hline $\mathrm{T}_{2}$ & $100 \%$ & $86,1 \%$ & $100 \%$ & $86,1 \%$ \\
\hline $\mathrm{T}_{3}$ & $80,6 \%$ & $97,2 \%$ & $100 \%$ & $77,8 \%$ \\
\hline $\mathrm{T}_{4}^{3}$ & $94,4 \%$ & $83,3 \%$ & $100 \%$ & $77,3 \%$ \\
\hline
\end{tabular}

$\mathrm{T}_{\text {c }}$ - controle; $\mathrm{T}_{1}$ - sem mulching e sem cobertura herbácea; $\mathrm{T}_{2}$ - com mulching sem cobertura herbácea; $\mathrm{T}_{3}$ - sem mulching com cobertura herbácea; $\mathrm{T}_{4}$ - com mulching e com cobertura herbácea.

$\mathrm{T}_{c}$ - control; $\mathrm{T}_{1}$ - non-mulching and non-herbaceous layer; $\mathrm{T}_{2}$ - mulching + non-herbaceous layer; $\mathrm{T}_{3}$ - non-mulching + herbaceous layer; $\mathrm{T}_{4}$ - mulching + herbaceous layer. 


\subsection{Crescimento em altura e diâmetro}

A alta mortalidade de Kielmeyera lathrophytum (pau-santo) no experimento impossibilitou uma análise confiável de crescimento dessa espécie e, portanto, os dados foram desconsiderados. As três espécies que mais cresceram em altura na área minerada são pioneiras: Inga marginata, Genipa americana e Tapirira guianensis. Elas apresentaram 500, 492 e 464\% de incremento, respectivamente, entre a época do plantio e o final da segunda estação chuvosa (Figura 1). O crescimento em altura de uma árvore é um bom indicator das condições presentes em uma cova e no sítio em que a planta se encontra (GONÇALVES et al., 2004). Além disso, espécies pioneiras e secundárias iniciais constumam absorver mais nutrientes aplicados a substratos e apresentar maior eficiência no uso deles do que espécies secundárias tardias e climácicas (POGGIANI e SCHUMACHER, 2004). Sendo a capacidade de absorção de nutrientes característica relacionada com potencial de crescimento e de síntese de biomassa de uma espécie (GONÇALVES et al., 2004)

I. marginata (ingá) e T. guianensis (pau-pombo) são espécies de Mata de Galeria (Quadro 1). Apesar disso, desenvolveram-se bem na área minerada, cuja fisionomia original era Cerrado stricto sensu. Segundo FELFILI et al. (2000), T. guianensis é uma espécie de crescimento rápido, classificada entre as espécies lenhosas prioritárias para a recuperação de áreas desmatadas do Distrito Federal, por apresentar, entre outras características, muito bom desenvolvimento a pleno sol (FELFILI e SANTOS, 2002). I. marginata é uma espécie conhecida pela excelente adaptação às condições adversas encontradas em áreas mineradas no Cerrado (CORRÊA, 2006). Genipa americana (jenipapo) começou a ser utilizada em projetos de revegetação de áreas mineradas no Distrito Federal há menos de uma década e mostrou um excelente desempenho neste projeto. O jenipapo ocorre naturalmente em Cerrado stricto sensu e Cerradão (MENDONÇA et al., 1998), fisionomias em que as espécies apresentam um crescimento da parte aérea mais lento do que as espécies típicas de mata. Entretanto, a altura final do jenipapo não diferiu significativamente das alturas finais do ingá e do pau-pombo (Figura 1), espécies pioneiras típicas de Mata de Galeria (Quadro 1).

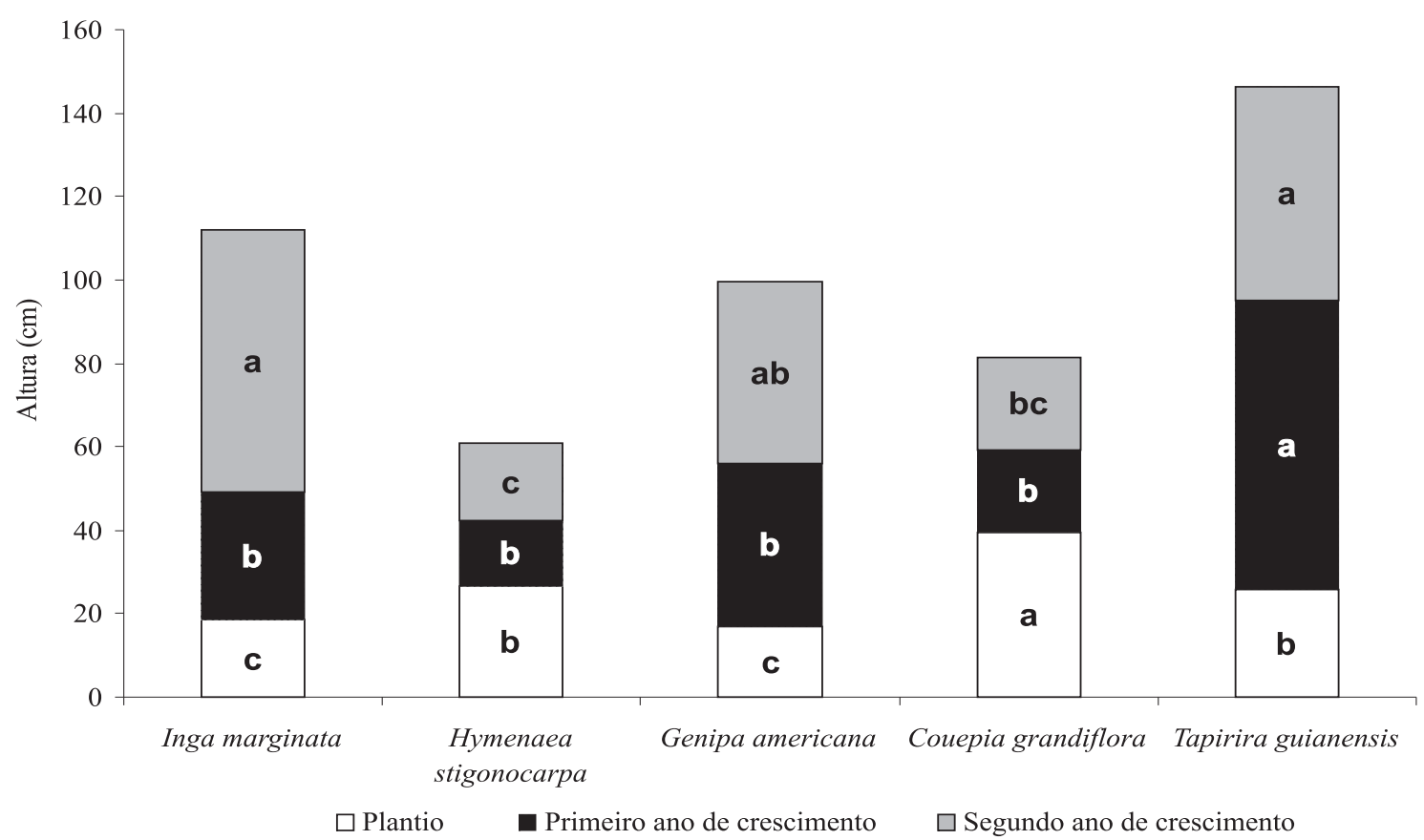

Figura 1 - Altura média das espécies por período avaliado, considerando todos os tratamentos. Médias de mesma letra em cada período avaliado não diferem estatisticamente pelo teste de Wilcoxon $(\mathrm{P}<0,05)$.

Figure 1 - Mean heights of species for each period, considering all treatments. Means of same letter for each period do not statistically differ according to Wilcoxon test $(P<0.05)$.

R. Árvore, Viçosa-MG, v.32, n.4, p.731-740, 2008 
Segundo FELFILI e SANTOS (2002), $H$. stigonocarpa (jatobá-do-Cerado) apresenta forte potencial para desenvolvimento a pleno sol, sendo considerada por esses autores uma espécie prioritária para a recuperação da vegetação do Distrito Federal. Apesar disso, seu crescimento neste experimento foi o menor observado entre as cinco espécies avaliadas. A demanda das plantas por nutrientes varia de acordo com a espécie, entre outros fatores. H. stigonocarpa é relatada como pouco exigente quanto à fertilidade do solo (LORENZI, 1992). Nesse sentido, o jatobá cresceu menos, pois espécies adaptadas a solos pouco férteis são menos infuenciadas pela aplicação de fertilizantes do que de espécies quimicamente mais exigentes (GONÇALVES et al., 2004).

Não se verificaram efeitos significativos dos tratamentos dados ao substrato minerado $\left(\mathrm{T}_{1} \mathrm{a} \mathrm{T}_{4}\right)$ sobre o crescimento em altura das espécies utilizadas (Figura 2). Apenas as mudas cultivadas na área controle ( $\left.\mathrm{T}_{\mathrm{c}}\right)$ apresentaram um crescimento médio inferior ao verificado nos demais tratamentos - $\mathrm{T}_{1}$ a $\mathrm{T}_{4}$ (Figura 2). Estabelecimento de estrato herbáceo sobre a superfície minerada e aplicação de cavaco de madeira sobre covas não exerceram efeitos significativos sobre crescimento em altura das plantas. Houve, entretanto, uma tendência de maior crescimento em altura das mudas cultivadas na metade da área em que o estrato herbáceo foi implantado - $\mathrm{T}_{3}$ e $\mathrm{T}_{4}$ (Figura 2).

Os tratamentos aplicados à área minerada $\left(\mathrm{T}_{1} \mathrm{a}\right.$
$\mathrm{T}_{4}$ ) não foram suficientes para que houvesse diferenciação significativa no crescimento em altura das mudas. A adubação feita nas covas permitiu que o crescimento se desse de forma independente dos tratamentos. Porém, à medida que as raízes das árvores demandarem maior volume de substrato, os tratamentos $T_{3}$ e $T_{4}$ (esacarificação e cobertura herbácea) provavelmente irão promover um maior crescimento das plantas em relação às árvores estabelecidas nos tratamentos $T_{1}$ e $\mathrm{T}_{2}$, pois as plantas destes últimos terão suas raízes confinadas às covas. Além disso, o estabelecimento de Stylosanthes pode ser responsável em um prazo mais longo, por diferentes graus de facilitação no processo de sucessão ecológica entre os tratamentos. Espera-se que a cobertura herbácea proporcione melhores condições à chegada e desenvolvimento de sementes e propágulos em relação à porção da área em recuperação que não recebeu essa cobertura (ALMEIDA e SÁNCHEZ, 2005).

Os quatro tratamentos adotados neste trabalho também não resultaram em diferentes crescimentos do diâmetro do caule das plantas. Esses resultados diferem dos obtidos por MOREIRA (2004), que verificou diferentes respostas de crescimento em diâmetro ao aplicar variados tratamentos a dezoito espécies em uma área minerada. $\mathrm{O}$ autor verificou que mudas implantadas em covas adubadas + estrato herbáceo (Crotalaria juncea) apresentaram maior incremento em diâmetro, em 24 meses de experimento, do que as mudas que receberam a mesma adubação, mas que não foram plantadas em consórcio com o estrato herbáceo.

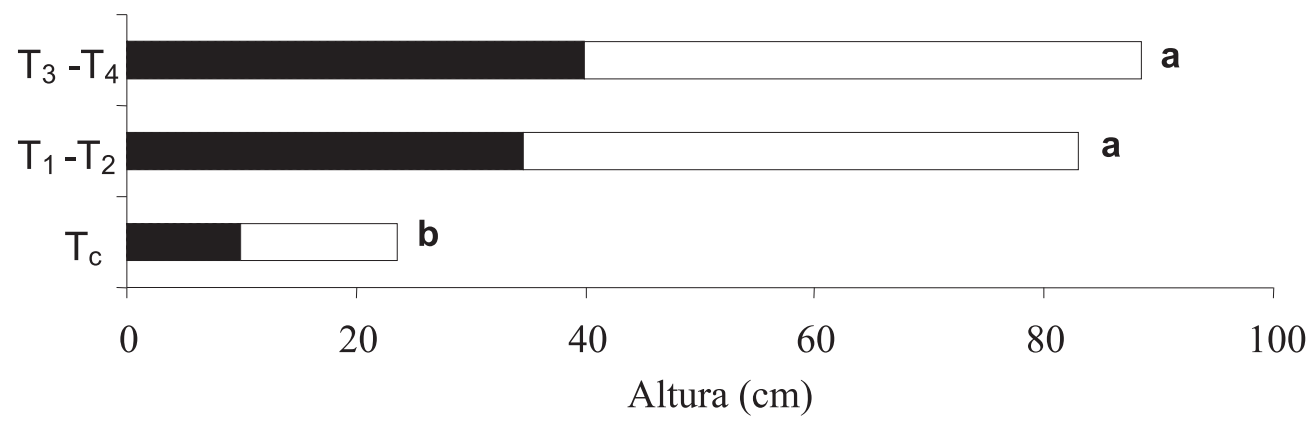

Primeiro ano de crescimento

Segundo ano de crescimento

$\mathrm{T}_{c}$ - controle; $\mathrm{T}_{1}-\mathrm{T}_{2}$ - tratamentos sem cobertura herbácea; $\mathrm{T}_{3}-\mathrm{T}_{4}$ - tratamentos com cobertura herbácea.

$\mathrm{T}_{\mathrm{c}}^{\mathrm{c}}$ - control; $\mathrm{T}_{1}-\mathrm{T}_{2}$ - treatments without herbaceous layer; $\mathrm{T}_{3}-\mathrm{T}_{4}^{4}$ - treatments with herbaceous layer.

Figura 2 - Altura média das espécies em dezoito meses de crescimento. Médias de mesma letra não diferem estatisticamente pelo teste de Wilcoxon $(\mathrm{P}<0,05)$.

Figure 2-Mean heights of species in eighteen months of development. Means of same letter do not statistically differ according to Wilcoxon test $(P<0.05)$. 
As espécies que mais cresceram em diâmetro foram G. americana e T. guianensis (Figura 3). Com base nos resultados de crescimento em altura e diâmetro, T. guianensis foi a espécie que melhor respondeu a todos os tratamentos (Figura 1 e Figura 3). H. stiginocarpa apresentou, mais uma vez, o menor crescimento em diâmetro do caule entre as cinco espécies avaliadas (Figura 3). De um modo geral, o crescimento do diâmetro do caule das plantas acompanhou seus respectivos incrementos em altura e as espécies de Cerrado stricto sensu (Quadro 1) cresceram menos em diâmetro que as espécies de mata, nutricionalmente mais exigentes.

Segundo SILVA et al. (1997), as maiores respostas à fertilização são de espécies com maiores taxas de crescimento, independentemente do grupo sucessional. Entretanto, os menores crescimentos observados neste trabalho referem-se a Hymenaea stigonocarpa (jatobádo-cerrado) e Couepia grandiflora (oiti), espécies de ocorrência natural em Cerrado stricto sensu, classificadas como secundárias (Quadro 1). RESENDE et al., (1999) afirmam que espécies de grupos sucessionais mais avançados respondem menos a adubações do que espécies pioneiras, fato verficado neste trabalho. As três espécies pioneiras (Quadro 1) apresentaram os maiores incrementos em altura e diâmetro do caule. O crescimento dessas espécies pode levar a mudanças nas condições de sombreamento, que favorecerão a introdução e desenvolvimento de espécies de estágios sucessionais mais avançados (ARAÚJO et al., 2005).

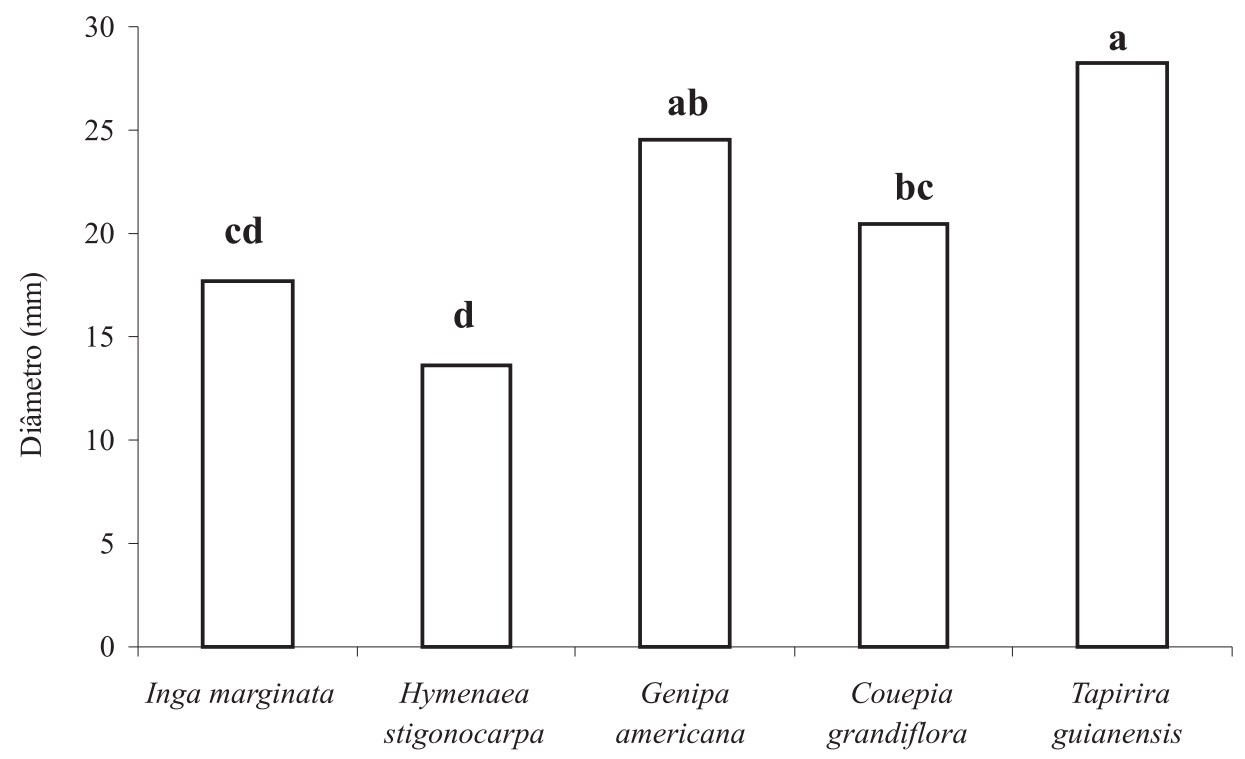

Figura 3 - Diâmetro médio das espécies, considerando todos os tratamentos. Médias de mesma letra não diferem estatisticamente pelo teste de Wilcoxon $(\mathrm{P}<0,05)$.

Figura 3 - Mean diameters of species for all treatments. Means of same letter do not statistically differ according to Wilcoxon test $(P<0,05)$.

\section{CONCLUSÕES}

- Relações ecológicas desarmônicas na área de Cerrado resultaram em mais mudas arbóreas mortas que a condição árida da área minerada.

- À exceção de Kielmeyera lathrophytum, todas as espécies testadas neste trabalho apresentaram percentuais de sobrevivência $=90 \%$. Ao se incluir $K$. lathrophytum, a percentagem de indivíduos mortos aumentou para valores entre 14 e $23 \%$, dependendo do tratamento.
- A aplicação de cobertura morta sobre as covas aumentou levemente a sobrevivência e as chances de estabelecimento das plantas na área minerada.

- Os tratamentos aplicados na área minerada cavaco de madeira sobre as covas e/ou implantação de cobertura herbácea sobre o substrato - não resultaram em significativas diferenças de incremento em altura e diâmetro das espécies testadas. Observou-se, porém, uma tendência de maior incremento em altura das espécies 
introduzidas nos tratamentos que utilizaram a cobertura herbácea sobre o substrato. Avaliações futuras devem ser feitas para confirmar ou refutar essa tendência.

- Tapirira guianensis, Inga marginata e Genipa americana apresentaram excelentes resultados de sobrevivência e desenvolvimento na área minerada entre as seis espécies testadas.

\section{REFERÊNCIAS}

ALMEIDA, R. O. P. O.; SÁNCHEZ, L. E. Revegetação de áreas de mineração: critérios de monitoramento e avaliação do desempenho. Rev. Árvore, v.29, n.1, p.47-54, 2005.

ANAND, M.; DESROCHERS, R. E. Quantification of restoration success using complex systems concepts and models. Conservation Biology, v.12, n.1, p.117-123, 2004.

ARAÚJO, F. S.; MARTINS, S.V.; NETO, J. A. M.; LANI, J. L.; PIRES, I. E. Florística da vegetação arbustivo - arbórea colonizadora de uma área degradada por mineração de caulim, em Brás Pires, MG. Rev. Árvore, vol.29, n.6, p.983-992, 2005.

BEGON, M; HARPER, J. L.; TOWNSEND, C. R. Ecology: individuals, populations and communities. Boston: Blackwell Scientific Publications, $2^{\circ}$ ed., 1990. 945p.

BITAR, O. Y. Avaliação da recuperação de áreas degradadas por mineração na região metropolitana de São Paulo. 1997. 185p. Dissertação (Doutorado em Engenharia de Minas). Escola Politécnica da Universidade de São Paulo/Departamento de Engenharia de Minas, São Paulo, 1997.

BORGES, A. L.; SOUZA, L. da S.; FANCELLI, M.; ALVES, E. J.; CALDAS, R. C.; SOUZA, J. Cobertura vegetal na melhoria das propriedades químicas e físicas dos solos e na produção da bananeira. EMBRAPA-CNPMF, Cruz das Almas, BA. 1995. 6p.

CAMPOS, H. Estatística experimental não paramétrica. $3^{\mathrm{a}}$ ed. Piracicaba: ESALQ, 1979. 343p.

CORRÊA, R. S. Recuperação de áreas degradadas pela mineração no Cerrado - Manual para revegetação. Brasília, Ed. Universa, 2006. 187p.
CORRÊA, R. S; MÉLO FILHO, B. Ecologia e recuperação de áreas degradadas no cerrado. Coleção Regio Montano Campestris. Brasilia, Ed. Paralelo 15, 1998. 178p.

CORRÊA, R. S.; BIAS, E. S.; BAPTISTA, G. M. M. Áreas degradadas pela mineração no Distrito Federal. In: CORRÊA, R.S.; BAPTISTA, G.M.M (Orgs.). Mineração e áreas degradadas no cerrado. Brasília, Ed. Universa, 2004. p.9-21.

CORRÊA, R. S.; MESQUITA, P. G. Comparação entre o crescimento de três espécies arbóreas de cerrado em área nativa e em área minerada. In: VII Congresso e Exposição Internacional sobre Florestas - Forest 2004, 2004. Brasília. Anais... Brasília: Revista do VII Congresso e Exposição Internacional sobre Florestas - Forest 2004. p. 52-54.

DURIGAN, G.; NOGUEIRA, J. C. B.

Recomposição de matas ciliares. São Paulo: Instituto Florestal, 1990. 14p.

EITEN, G. Vegetação do Cerrado. In: NOVAES PINTO, M. (Org.). Cerrado: caracterização, ocupação e perspectivas. $2^{a}$. ed. Brasília, Ed. Universidade de Brasília, 1994. p.7-73.

EITEN, G. Vegetação natural do Distrito Federal. Brasília: Ed. Universidade de Brasília/ SEBRAE, 2001. 162p.

EMBRAPA. Recomendações para o estabelecimento e utilização do Stylosanthes guinensis cv. Mineirão. EMBRAPA-CPAC. Comunicado Técnico, 67; EMBRAPA-CNPGC. Comunicado Técnico, 49. Planaltina/Campo Grande, 1993. 6p.

EMBRAPA. Sistema brasileiro de classificação de solos. Embrapa-CNPS, Centro Nacional de Pesquisa de Solos. Rio de Janeiro, RJ, 1999. 412p.

FELFILI, J. M. Subsídios para a recuperação da vegetação. In: UNESCO. Vegetação no Distrito Federal - tempo e espaço. Brasília: UNESCO, 2000. 74p.

FELFILI, J. M.; RIBEIRO, F. J.; FAGG, C. W.; MACHADO, J. W. Recuperação de matas de galeria. Brasília: Embrapa Cerrados/MMA. Documento $n^{\circ} 21,2000.45 p$.

R. Árvore, Viçosa-MG, v.32, n.4, p.731-740, 2008 
FELFILI, J. M.; SANTOS, A. A. B. Direito ambiental e subsídios para a revegetação de áreas degradadas no Distrito Federal. Universidade de Brasília/Departamento de Engenharia Florestal. Comunicações técnicas florestais, v.4, n.2, Brasília, 2002. 135p.

GANADE, G.; BROWN, V. K. Succession in old pastures of Central Amazonia: role of soil fertility and plant litter. Ecology, v.83, n.3, p.743-754, 2002.

GOEDERT, W. J.; CORRÊA, R. S. Usos, degradação e qualidade do solo. In: CORRÊA, R.S.; BAPTISTA, G.M.M (Orgs.). Mineração e áreas degradadas no cerrado. Brasília, Ed. Universa, 2004. p.159-172.

GONÇALVES, J. L. M.; SANTARELLI, E. G.; NETO, S. P. M.; MANARA, M. P. Seedling production of native species: substrate, nutrition, shading, and fertilization. In: GONÇALVES, J.L.M. e BENEDETTI, V. (orgs). Forest nutrition and fertilization. Piracicaba, Instituto de Pesquisas Florestais e Estudos Florestais, 2004. p.307-345.

KAGEYAMA, P.; GANDARA, F. B. Recuperação de áreas ciliares. In: Rodrigues, R.R.; Leitão Filho, H. de F. (eds) Matas ciliares: conservação e recuperação. São Paulo: Editora da Universidade de São Paulo/Fapesp, 2001. p.249-271.

LORENZI, H. Árvores brasileiras: manual de identificação e cultivo de plantas arbóreas nativas do Brasil. Nova Odessa: Plantarum, 1992. 352 p.

MALTONI, K. L.; VALÉRIO FILHO, W. V. Contribuições da revegetação de áreas de empréstimo para as características químicas do subsolo. In: IV Simpósio Nacional sobre Recuperação de Áreas Degradadas. Anais... Blumenau: FUBRA/SOBRADE, (CD-ROM), 2000.

MENDONÇA, R. C. et al. Flora vascular do cerrado. In: SANO, S.M.; ALMEIDA, S.P. (Eds.) Cerrado, ambiente e flora. Planaltina: Embrapa, 1998. p.289-556

MOREIRA, P. R. Manejo do solo e recomposição da vegetação com vistas a recuperação de áreas degradadas pela extração de bauxita, Poços de Caldas, MG. 2004. 139p. Dissertação (Doutorado em Ciências Biológicas). Instituto de Biociências da Universidade Estadual Paulista “Julio de Mesquita Filho”, Campus de Rio Claro, São Paulo, 2004.

R. Árvore, Viçosa-MG, v.32, n.4, p.731-740, 2008

\section{R. Arvore, Viçosa-MG, v.32, n.4, p.731-740, 2008}

MOTTA, M. L.; BENVENUTTI, R. D.; ANTUNES, E. C. Aplicação dos estudos fitossociológicos ao reflorestamento ciliar do Vale do Rio Turvo, GO. In: Simpósio Nacional de Recuperação de Áreas Degradadas, 3., Ouro Preto. Do Substratoao ao solo: trabalhos voluntários. Viçosa: Universidade Federal de Viçosa, 1997. p. 558-571.

OLIVEIRA, C. A. P.; SOUZA, C. M. Influência da cobertura morta na umidade, incidência de plantas daninhas e de broca-do-rizoma (Cosmopolites sordidus) em um pomar de bananeiras (Musa spp.). Revista Brasileira de Fruticultura, Jaboticabal, v. 25, n. 2, p. 345-347, 2003.

PIÑA-RODRIGUES, F. C. M.; LOPES, L.; BLOOMFIELD, V. K. Análise do desenvolvimento de espécies arbóreas da Mata Atlântica em sistema de plantio adensado para a revegetação de áreas degradadas em encosta, no entorno do Parque Estadual do Desengano (RJ). In: SIMPÓSIO NACIONAL DE RECUPERAÇÃODE ÁREAS DEGRADADAS - III SINRAD, 1997, Ouro Preto. Anais... Curitiba: Sociedade Brasileira de Recuperação de Áreas Degradadas/Sobrade \& Universidade Federal de Viçosa/UFV, 1997, p.283-291.

POGGIANI, F.; SCHUMACHER, M. V. Nutrient cycling in native forests. In: GONÇALVES, J.L.M. e BENEDETTI, V. (orgs). Forest nutrition and fertilization. Instituto de Pesquisas Florestais e Estudos Florestais, Piracicaba, 2004. p.285-305.

RESENDE A. V., NETO A. E. F., MUNIZ J. A., CURI, N., FAQUIN, V. Crescimento inicial de espécies florestais de diferentes grupos sucessionais em resposta a doses de fósforo. Pesquisa Agropecuária Brasileira, v.34, n.11, p.2071-2081, 1999.

SAS INSTITUTE. SAS OnlineDoc, Version 8. Cary: 1999.

SILVA, M. P.; ZIMMER, A. H. Avaliação agronômica de consorciações de braquiárias e Andropogon gayanus com novos acessos de estilosantes sob pastejo. In: Reunião Anual da Sociedade Brasileira de Zootecnia, 41., 2004, Campo Grande. Anais... Campo Grande: Sociedade Brasileira de Zootecnia, 2004. p.212-220.

SILVA, I. R.; FURTINI NETO, A. E.; CURI, N.; VALE, F. R. Crescimento inicial de quatorze espécies florestais nativas em resposta à adubação potássica. Pesquisa Agropecuária Brasileira, Brasília, v.32, n.2, p.205-212, 1997. 